\title{
УДК 656.072/.073-048.34
}

\section{Г. В. САГИРОВ ${ }^{1}$, Г. Я. МОЗОЛЕВИЧ ${ }^{2} *$ А. М. ОКОРОКОВ ${ }^{3 *}$}

${ }^{1 *}$ Студент факультета «Управление процессами перевозок», Днепропетровский национальный университет железнодорожного транспорта имени академика В. Лазаряна, ул. Лазаряна, 2, 49010, г. Днепр, Украина, тел. +38 (056) 3731520 , эл. почта sagirov_3@ mail.ru, ORCID 0000-0001-5787-8971

$2^{*}$ Каф. «Станции и узлы», Днепропетровский национальный университет железнодорожного транспорта имени академика В. Лазаряна, ул. Лазаряна, 2, 49010, г. Днепр, Украина, тел. +38 (056) 793-19-21, эл. почта diit_rmv@ukr.net, ORCID 0000-0002-4715-1645

${ }^{3 *}$ Каф. «Управление эксплуатационной работой», Днепропетровский национальный университет железнодорожного транспорта имени академика В. Лазаряна, ул. Лазаряна, 2, 49010, г. Днепр, Украина, тел. +38 (056) 373 15 04, эл. почта andrew_okorokoff@mail.ru, ORCID 0000-0002-3111-5519

\section{ОСНОВНЫЕ КРИТЕРИИ И ЗАДАНИЯ ІТ-СИСТЕМЫ В ЛОГИСТИКЕ 5PL ПРОВАЙДЕРА}

Цель. Создание нового класса логистического провайдера, который сможет предложить комплекс всех логистических услуг благодаря своему глобальному пространству, которое включает в себя информацию о полном рынке логистических услуг. Методика. Решение проблем выполнено стандартными эмпирическими методами исследования, таких как сравнение и анализ, а также была использована стратегия семикратного поиска. Результаты. В процессе анализа были выведены требуемые критерии пятого класса логистического провайдера. Модернизация системы оптимизации логистических процессов посредством внедрения мощного IT-аппарата. Создание продукта для обработки логистических данных, который сможет обеспечить максимальную оптимизацию логистических цепей. Научная новизна. Научная новизна работы состоит в усовершенствовании методов анализа материального потока и в возможности практического применения в современных реалиях развития логистических систем. Практическая значимость. Результаты работы могут использоваться для создания логистической системы.

Ключевые слова: 5PL; транспорт; логистика; провайдер.

\section{Введение}

Логистика играет основополагающую роль в развитии мировой экономики. Слово «логистика» звучит каждый день, но у большинства населения оно вызывает в голове только мысли о том, как быстро и эффективно доставить товар из одной точки в другую. Но это всего лишь верхушка айсберга - дела обстоят куда сложнее.

С развитием промышленности и с увеличением производства любая компания, завод или предприятие сталкивается с некоторыми проблемами. Ведь в частности, производство зависит от жестко фиксированных временных рамок, и порой не позволительны запоздания даже в несколько секунд. Соответственно, на сегодняшний день повышается роль логистики. В связи с этим на рынке с каждым днем появляется большое количество логистических компаний, которые вынуждены развиваться в ногу со временем и предоставлять услуги, соответствующие заявленному классу.

В данный момент в логистических процессах нужно опираться на три главных фактора развития стандарта 5PL. Они несомненно должны представлять собой развивающуюся сис- тему, иметь четкие и обозначенные пути развития:

- межнациональные перевозки, и всяческое их упрощение;

- создание единого информационного и технического пространства для функционирования 5PL оператора;

- внедрение инновационных технологий по контролю перемещения данных материального потока.

\section{Международные перевозки}

Современному логистическому провайдеру необходимо межнациональное развитие, которое позволит транспортировать необходимый товар с минимальными затратами в кратчайшие сроки, как начиная от отправки небольшой посылки, так и заканчивая маршрутной отправкой определенного сырья.

При международных перевозках логистика сталкивается с такими проблемами, как таможенные пошлины, различные требования к документам, неподготовленность и недостаточная разработка маршрута транспортировки. В последствии все это сказывается на оптимизации работы, а как следствие вытекают дополните-

() Сагиров Г. В., Мозолевич Г. Я, Окороков А. М 2016 
льные затраты и проблемы, приводящие к повышению стоимости услуг на транспортировку, а в некоторых случаях - вообще, на невозможность перевозки, как таковой.

Для решения всех этих проблем есть несколько путей развития. На данный момент в связи с современным курсом развития мировой политики и торговых отношений, крайне выгодно быть подготовленным к грядущим изменениям.

В период времени с 2014 по 2016 год весь мир наблюдает за внедрением разнообразных торгово-экономических соглашений между странами. Ярким примером является Транстихоокеанское и Трансатлантическое партнерство. Но это не первые подобные объединения стран в зону единой экономической и торговой зон. Есть также такие организации, как АСЕАН, АТЭС и БРИКС, и конечно же Европейская экономическая зона (ЕЭЗ).

Цель всех этих организаций внедрение единых стандартов в сфере производства, торговли, промышленности и т.п. Но для логистики это несет другой смысл.

Во-первых, это упростит транспортировку груза в межнациональном сообщении.

Во-вторых, это создаст новые рынки для оборота товаров, что незамедлительно приведет к возрастанию потребностей производителей в грузовых перевозках.

Также следует отметить важность рассмотрения наиболее экономически выгодного транспорта для межнациональных перевозок. К основным видам транспорта, используемых для перевозки грузов относятся: автомобильный; железнодорожный и морской. Но благодаря своей гибкости автомобильный транспорт является приоритетным для логистического провайдера.

Автомобильный транспорт традиционно специализируется на перевозках на небольшие расстояния. С развитием нового типа интермодальных перевозок, внедрением контейнерных и пакетных технологий, грузовых терминалов автомобильный транспорт стал активно использоваться и при перевозках грузов на дальние расстояния.

\section{IT-аппарат оптимизации логистических процессов}

На сегодняшний день мировые лидеры логистики предоставляют все услуги, которые соответствуют уровню 3PL и 4PL.

Согласно данным Inbound Logistics на рынке 3PL провайдеров наблюдаться следующая ситуация [6]:
- 80 \% грузоотправителей утверждают, что первенствующим требованием для них к провайдеру является качество предоставляемых услуг. И лишь $20 \%$ утверждают, что при сотрудничестве с логистической компанией они основываются на цену услуг.

При этом 51 \% от грузоотправителей утверждают, что плохое обслуживание клиентов является первой причиной разрыва сотрудничества. Эти результаты свидетельствуют о том, что компании готовы платить за качественный сервис. Партнерские отношения, построенные вокруг финансовых показателей сопряжены с риском.

Этот акцент на сервис ведет к принужденным заключениям договоров с большим количеством логистических компаний.

Следует отметить, что 90 \% логистических компаний считают, что клиенты должны рассмотреть возможность партнерства с более чем одним поставщиком услуг, в то время, как только $10 \%$ заключают, что клиенты должны работать с одним партнером. При этом грузоотправители придерживаются одного мнения: 84 \% используют более одного 3PL провайдера, в то время, как только $16 \%$ из них пользуются услугами одной кампании.

Таким образом, клиенты обращаются к 4PL провайдерам, которые в свою очередь берут на себя управление и теми 3PL провайдерами, услугами которых пользуются сами клиенты.

Лидерами рынка логистических услуг являются такие компании как DHL, Kuehne \& Nagel, DB Schenker Logistics. Также есть всем известная FedEx. Большинство из них предоставляют такую услугу, как контрактная логистика. Ведь именно она является основной для 4PL провайдера.

Однако новейшие разработки в области сетевых соединений и интеллектуального программного обеспечения баз данных в совокупности с развитием аутсорсинга и стратегических партнерств среди ведущих транснациональных компаний привели к появлению нового уровня логистического аутсорсинга - 5PL (Fifth Party Logistics).

Деятельность 5PL-провайдеров обеспечивается поддержкой современных сетевых компьютерных технологий. Как и 4PL, 5PL не обладают материальными активами и направлены на стратегическое управление цепями поставок, однако в большей степени ориентированы на модель «виртуального предприятия».

В основе IT системы 5PL провайдера должна присутствовать следующая циклическая 
цепь, которая будет основным средством улучшения и оптимизации перевозок. Данная цепь представлена на рис. 1. Она должна обеспечивать последовательность обработки заказа такого уровня, который позволит при поступлении очереденого заказа использовать всю информацию, которая находиться в системе заказов, при этом находя заказ с похожими критериями (пункт назначения, пункт прибытия, промежуточные пункты, время пути, расстояние, тип транспорта).

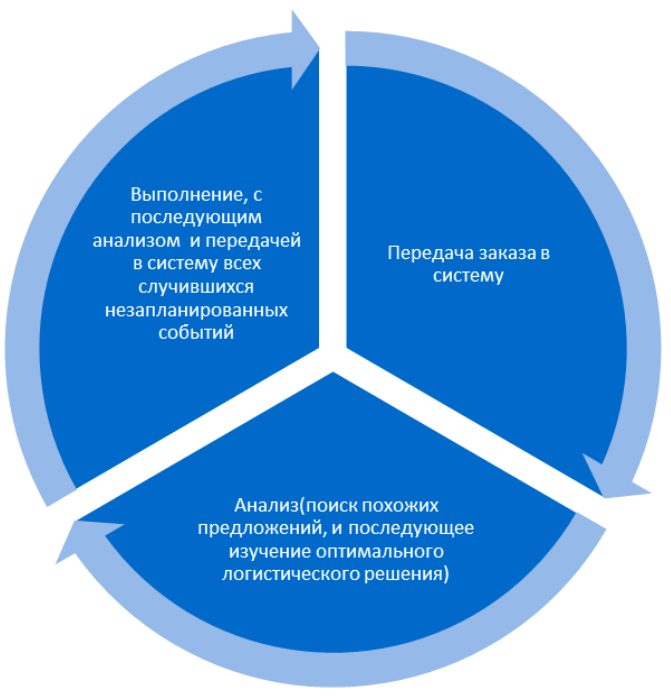

Рис.1. Цепь принятия и анализа заказов

\section{Технологии 5PL}

Сейчас на мировом рынке таких провайдеров единицы. Наглядным примером крупного 5PL-провайдера может служить новозеландская компания Contract Warehousing New Zealand Limited.

Contract Warehousing Group прошла путь от простых автомобильных перевозок и грузообработки в 70-х гг. прошлого века до провайдера складских и логистических решений (3PL) и услуг по управлению цепями поставок (4PL) с годовым оборотом свыше 3 млн. USD и более 90 клиентами в Новой Зеландии и Австралии. В 2010 г. компания подписала контракт с крупнейшим австралийском поставщиком транспортного и логистического программного обеспечения TransLogix о внедрении нового программного продукта Integrated Sapphire Transport \& Logistics Management Suite.

Приобретенные компанией модули по управлению транспортными, складскими, бухгалтерскими и web-услугами позволили ей выйти на новый уровень аутсорсинга. Например, на базе модуля Sapphire Customer Web Portal компания предоставляет своим кли- ентам услугу по использованию клиентского web-портала, где клиенты могут самостоятельно: размещать заказы и информацию о вакансиях; отслеживать состояние заказов; просматривать котировки, доказательства поставки, накладные, отчеты; отслеживать уровень остатка на счетах; отслеживать уровень запасов и их передвижение; распечатывать счета-фактуры, отчеты и др. документы. [4]

Тем не менее все это фундаментальные критерии, и вовсе не значат, что провайдер будущего должен этим ограничиваться. В СанктПетербурге в 2014 году прошел IT- конкурс в котором победу одержал проект VeeRoute.

VeeRoute - это сервис по оптимизации транспортной логистики. С его помощью можно оптимизировать маршруты внутригородских перевозок и оперативно управлять ими в режиме онлайн. В системе заложены необходимые исходные данные, такие как исторические сведения о пробках, время пребывания курьера у клиента в зависимости от типа груза и многие другие. Все эти параметры помогают в автоматическом режиме проложить оптимальный маршрут для водителя [3].

Как видно, в самом проекте заложена хорошая идея оперативного управления базой данных с целью оптимизации работы цепей поставок. Этот принцип обработки заказов позволяет сделать более точный анализ всех факторов доставки груза.

Также следует помнить о GPS-трекинге транспорта, который активно используется в странах Европы большинством логистических структур. Для наглядности следует рассмотреть перечень достоинств этой технологии для осуществления логистических услуг:

- контроль пробега транспорта;

- контроль расхода топлива;

- удобное отслеживание груза и транспорта;

- возможность анализа маршрута груза;

- увеличение эффективности работы транспортного парка.

Для использования данной системы единицу транспорта оборудуют навигационными приемниками (трекерами), которые позволяют в режиме реального времени (дискретизация порядка 10 секунд) определить местоположение единицы транспорта (с точностью до 10 метров) и передать данные (широту, долготу, высоту над уровнем моря, скорость и ускорение) на телематический сервер для дальнейшей обработки посредством каналов беспроводной связи (таких как мобильные пакетные GSMсети, цифровые CSD-каналы, WI-FI сети). Пос- 
ле сбора, информация сохраняется в базе данных телематического сервера и по запросу выдаётся диспетчеру. Диспетчер в процессе контроля перемещения транспорта может устанавливать голосовую связь с водителем, удаленно заглушить двигатель автомобиля и многое другое. Подобное расширение возможностей транспортного мониторинга позволяют не просто получать информацию о проблемах и нарушениях, влияющих на транспортные издержки компании, но и оперативно нивелировать их [5].

\section{Выводы}

Украина всегда обладала необходимым потенциалом для достижения лидерства на рынке логистики. Её IT-специалисты являются одними из лучших в Европе. Местоположение может послужить только преимуществом. Из этих соображений наша страна может навязать конкуренцию, как странам Европы, так и непосредственно странам-соседям. Соответственно, нет каких-либо препятствий для создания своего логистического провайдера, который будет лидером на рынке.

Грядет новая техногенная эра, в которой все большее значение будут придавать автоматизации и роботизации процессов. И эта напрямую касается логистики, если человек хочет не потеряться в гонке технологий, то уже сейчас следует понимать возможности 5PL, которые привнесут не только оптимизацию и улучшения для транспортных перевозок.

На мой взгляд, 5PL провайдер, при правильном построении системы взаимодействующих элементов, может не только стать лидером на рынке логистики, но непременно поглотить всех остальных. При создании любой логистического структуры самым важным шагом является выбор критериев оптимизации, которые будут способствовать улучшению всей логистической цепи.

Приоритетными направлениями для 5PL являются:

- развитое международное сообщение;

- база данных, которая будет включать в себя систему взаимодействия всех факторов, влияющих на оптимизацию транспортных процессов;

- технологии, которые способствуют оптимизации перемещения материального потока, из которых можно выделить GPS-трекинг и мониторинг, электронную базу документации и самое важное - IT-структуру, которая будет информационно связывать все транспортные цепочки.

Тот, кто первым сможет создать такую рабочую структуру, тот и дальше будет задавать темп развития всей логистике.

\section{БИБЛИОГРАФИЧЕСКИЙ СПИСОК}

1. Бауэрсокс Дональд Дж., Логистика: интегрированная цепь поставок / Бауэрсокс Дональд Дж., Клосс Дейвид Дж. : Пер. с англ. - Москва : ЗАО «Олимп-Бизнес», 2001. - 640 с.

2. Гаджинский, А. М. Логистика : Учеб. для высших и средних спец. учеб. заведений. / А. М. Гаджинский. 3-е изд., перераб. и доп. - Москва : Информационно-внедренческий центр «Маркетинг», 2000. - 375 c.

3. VeeRoute- победитель it-трека. Блог компании GenerationS-2014 [Электрон. ресурс]. - Режим доступу : https://habrahabr.ru/company/generations2014/blog/241505/

4. Contract Warehousing : 5PL - the way of the future [Электрон. peсурс]. - Режим доступу : http://www.cwlnz.co.nz/latest-news/5pl---the-way-ofthe-future/

5. Богданов, M. Р. Применения GPS/ГЛОНАСС : Учебное пособие / М. Р. Богданов. - Долгопрудный : ИД «Интеллект», 2012 г. - 136 с

6. Market Research: 3PL Perspectives 2014 [Электрон. pесурс]. - Режим доступу : http://www.inboundlogistics.com/cms/article/marketresearch-3pl-perspectives-2014/

7. Hosie P., Egan V., Li Y., Drivers of Fifth Party Logistics (5PL) Service Providers for Supply Chain Management, School of Management, Curtin University of Technology, Perth 2007

8. Окороков, А. М. Використання супутникових систем позиціонування об'єктів для удосконалення управління вантажними комплексами / А. М. Окороков // Транспортні системи і технології перевезень. - 2013. - Вип. 5. - С. 54-57. - doi : 10.15802/tstt2013/19279

9. Hosie, P. Determinants of fifth party logistics (5PL): service providers for supply chain management / Hosie P. et al // International Journal of Logistics Systems and Management. - 2012. - T. 13. - №. 3. - P. 287-316.

10. Fulconis, F. Exploring new competences in the logistics industry: the intermediation role of 4PL / F. Fulconis, L. Saglietto, G. Paché // Supply Chain Forum: An International Journal. - Taylor \& Francis, 2006. - T. 7. - № 2. - C. 68-77.

11. Garver, M. S. Logistics research methods: employing structural equation modeling to test for construct validity / M. S. Garver, J. T. Mentzer //Journal of business logistics. - 1999. - T. 20. - №. 1. - C. 33.

Статья рекомендована к публикащии д.т.н., проф. Альошинським С.С. (Україна)

Поступила в редколлегию 21.11.2016.

Принята к печати 25.11.2016. 


\section{ОСНОВНІ КРИТЕРІЇ І ЗАВДАННЯ ІТ-СИСТЕМИ У ЛОГІСТИЦІ 5РL ПРОВАЙДЕРА}

Мета. Створення нового класу логістичного провайдера, який зможе запропонувати комплекс всіх логістичних послуг завдяки своєму глобальному простору, який поєднує в собі інформацію по всьому ринку логістичних послуг. Методика. Рішення проблем виконано стандартними емпіричними методами дослідження, таких як порівняння і аналіз, а також була використана стратегія семиразового пошуку. Результати. У процесі аналізу були виведені необхідні критерії п'ятого класу логістичного провайдера. Модернізація системи оптимізації логістичних процесів за допомогою впровадження потужного IT-апарату. Створення продукту для обробки логістичних даних, який зможе забезпечити максимальну оптимізацію логістичних ланцюгів. Наукова новизна. Наукова новизна роботи полягає в удосконаленні методів аналізу матеріального потоку і в можливості практичного застосування в сучасних реаліях розвитку логістичних систем. Практична значимість. Результати роботи можуть використовуватися для створення логістичної системи.

Ключові слова: 5PL; транспорт; логістика; провайдер.

G. V. SAHIROV, G. Y. MOZOLEVICH, A. M. OKOROKOV

\section{MAIN CRITERIA AND TASK IT-SYSTEMS IN LOGISTICS 5PL PROVIDER}

Purpose. Creating a new class of a logistics provider who can offer a range of all logistic services through its global space combines information on all the logistics market. Methods. Troubleshooting performed by standard empirical research methods, such as comparison and analysis, as well as seven-time search strategy was used. Results. In an analysis of the necessary criteria were derived fifth grade logistics provider. Modernization of optimizing logistics processes by implementing powerful IT-system. Creating a product for the treatment of logistics data that will provide maximum optimization of logistic chains. Scientific novelty. The scientific novelty of this work compare in improving of the material flow analysis and the possibility of practical application in today's realities of logistics systems. The Practical significance. The results can be used to create a logistic system.

Keywords: 5PL; transport; logistics; provider. 